\title{
Vioxx award good news for Canadian lawsuits
}

A Texas jury's decision to award US\$2 53 million to a widow who sued pharmaceutical giant Merck \& Co. should help Canadians pursue their own lawsuits against the maker of rofecoxib (Vioxx), says a Canadian lawyer.

On Aug. 19, the jury found Merck liable for the death of Robert Ernst, who died suddenly of an arrhythmia after taking rofecoxib for 8 months, and awarded widow Carol Ernst US\$24 million for pain and suffering and another US\$229 mil$\approx$ lion in punitive damages.

The lawyer representing Ernst relied on a paper trail that documented concerns Merck scientists expressed about the drug's cardiovascular effects. Those documents dated from 2

\section{News @ a glance}

SARS suit: An Ontario Superior Court judge has ruled that 2 lawsuits concerning Ontario's handling of the 2003 SARS outbreak can proceed. The lawsuits include a \$600-million class action by nurse Andrea Williams, who became infected while undergoing a surgical procedure in May 2003 and a \$12-million action brought by the family of nurse Nelia Laroza, who died of SARSrelated complications in June. Both nurses were infected during the second wave of the disease. The plaintiffs, both of whom contracted SARS at North York General Hosptial in Toronto, claim the province pressured WHO to lift its travel advisory prematurely because of its adverse effect on tourism.

No free travel: Beginning in January, Canada's 50 researchbased pharmaceutical companies (Rx\&D) will no longer pay physicians to attend Canadian years before Merck began marketing rofecoxib in 1999. The company pulled the drug from the market in September 2004 after a clinical trial indicated that it increased the risk of heart attack or stroke.

More than 20 million people worldwide took the drug. There are more than 4200 other rofecoxib cases pending against Merck in the United States and an estimated 50 claims in Canada, where both individual lawsuits and class actions are in the works. Analysts estimate the total litigation represents as much as US\$50 billion in liability for the company. Merck's lawyers say they will vigorously defend every case; they are appealing the Texas verdict.

Windsor, Ont., lawyer Greg
Monforton is representing more than 200 Canadians who suffered a stroke or heart attack or who had family members who died while taking rofecoxib.

"We believe that most, if not all, of the documents produced in the Ernst case will be admissible in our Canadian courts because they are relevant to Merck's conduct from the time of rofecoxib's development, approval and worldwide sales, right through until its withdrawal," says Monforton.

"In essence, these cases all revolve around the same central issues: What did Merck know, when did it know it, and what did it do with this information?" Monforton says. - Laura Eggertson, CMAJ conferences or educational sessions. $\mathrm{Rx} \& \mathrm{D}$ is considering extending the ban to international events as well. During an education session at the CMA annual meeting in August, Rx\&D President Russ Williams said the ban conforms to the CMA Code of Ethics. In order to be a full partner in the health care system, the pharmaceutical industry "needs to be seen to be ethical," Williams said.

Fewer smokers: The number of Canadians who smoke declined by 200000 between 2003 and 2004, according to Statistics Canada's Canadian Tobacco Use Monitoring Survey. An estimated 5.1 million Canadians, or $20 \%$ of the population aged 15 and older, reported smoking daily or occasionally in 2004. The year before, $21 \%$ or 5.3 million Canadians used tobacco. The percentage of young women (aged 20-24) who smoke declined by $5 \%$ to $25 \%$, during the same period.

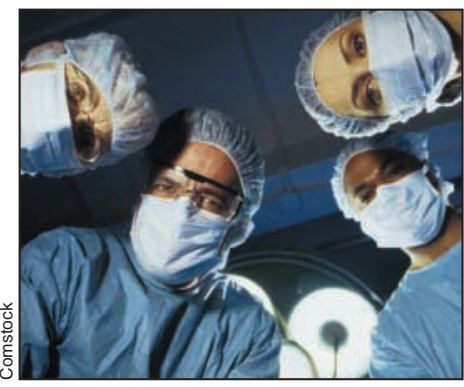

Physician supply: Canada's total number of doctors has kept pace with population growth since the late 1990s, reports the Canadian Institute for Health Information. New data show a $5 \%$ increase in the number of physicians between 2000 and 2004. However, the average age of physicians increased from 48 to 49 years and the proportion under age 40 dropped $13 \%$. CIHI also reported that for the first time since 1969, more physicians returned to Canada than moved abroad (317 v. 262) in 2004. Compiled by Barbara Sibbald, CMAJ 